\title{
Analysis of Hybrid Energy Storage System for Hybrid Electric, Battery Electric and Plugin Hybrid Electric Vehicles using Bidirectional DC/DC converter
}

\author{
Vijaya Krishna Muragani ${ }^{1}$, and Anil Kumar Rajagiri ${ }^{1}$ \\ ${ }^{1}$ EEE Department, GRIET, Hyderabad
}

\begin{abstract}
This paper deals with the Hybrid Energy Storage System (HESS) for Battery Electric, Hybrid and Plug-in Hybrid Electric Vehicles. Its performance is compared with conventional HESS design and also only Battery design, conventional design uses a bigger dc/dc converter between Battery and Ultracapacitor to satisfy the peak power demands in the real time, In this analysis a smaller $\mathrm{dc} / \mathrm{dc}$ converter is used which maintains the voltage of ultracapacitor higher than the battery voltage by working as controlled energy pump. Battery will provide power directly only when voltage of the Ultracapacitor drops below the voltage of the Battery. Therefore, a constant and smooth load profile can be created for the battery. For the proposed HESS system Simulation results are presented to verify.
\end{abstract}

\section{1 introduction}

The world is developing by ensuring proper usage of advanced technologies for Electric Vehicles. The increase of vehicles has mainly caused major problems like traffic jams, $\mathrm{CO}_{2}$ emissions, and therefore the extinction of fossil fuels. Decarbonization plays a crucial role in reducing the $\mathrm{CO}_{2}$ emissions from transport vehicles. Electric vehicles are attracting attention within the vehicles market due to their low emissions of $\mathrm{CO}_{2}$ and efficient reduction of $\mathrm{CO}_{2}$ emission. The EV has higher engine efficiency and doesn't emit pollutants because it doesn't have any fuel. So, it's referred to as a zero-emission vehicle.

Energy storage systems (ESSs) have more importance in hybrid electric vehicles. Batteries, Fuel cells, Hybrid combinations are some of the commonly used among the energy storage systems. In Battery based Energy storage systems, the battery power density should be maintained higher enough to satisfy the peak power demand. Batteries with higher power densities also are available within the market, they're much costly than lower power density batteries. The solution to this problem is to increase the size of the battery [1]. However, this also increases the cost. In addition, balancing the cells in a battery system is an issue which concerns the battery life. Applications of instantaneous power input and output, find the batteries affected by the frequent charging and discharging operations. which affects the battery life. For this type of system it is necessary to keep an additional Energy Storage System which is more stronger to handle the surge current.

Hybrid energy storage systems have been analysed to reduce such problems. The general idea of a Hybrid

\footnotetext{
*Vijay Krishna Muragani: vijaykrishnam6@gmail.com
}

Energy Storage System(HESS) is to combine ultracapacitors (UCs) and batteries to achieve better overall performance [1]. Ultracapacitors have a higher power density and lower energy density. This combination gives better performance when compared to the use of them alone.

One of the example is the hybrid energy storage system (HESS) using battery and Ultracapacitor, where the battery is used for compensation of low-frequency power fluctuations and the ultracapacitor is used for compensation of high-frequency power fluctuations [2]. Many researchers have demonstrated the efficiency of battery-ultracapacitor hybrid energy storage systems using theoretical models and experimental prototypes, however this is due to the drastically differing operational parameters of ultracapacitors and batteries. There are a variety of topologies that use both battery and UC hybrid energy storage systems, each with its own set of benefits and drawbacks, and researchers are still looking at them.

Table 1. Characteristics of Battery Cells.

\begin{tabular}{|c|c|c|c|c|}
\hline Chemistry & $\begin{array}{c}\text { Nominal } \\
\text { Cell } \\
\text { Voltage } \\
\text { (Volt) }\end{array}$ & $\begin{array}{c}\text { Energy } \\
\text { Density } \\
\text { (Wh/Kg) }\end{array}$ & $\begin{array}{c}\text { Power } \\
\text { Density } \\
\text { (Kw/kg) }\end{array}$ & $\begin{array}{c}\text { Life } \\
\text { cycle } \\
\text { (Times) }\end{array}$ \\
\hline Lead Acid & 2 & $30-40$ & 0.18 & Up to 800 \\
\hline
\end{tabular}




\begin{tabular}{|c|c|c|c|c|}
\hline Ni-Mh & 1.2 & $55-80$ & $0.4-1.2$ & $\begin{array}{c}\text { Up to } \\
1000\end{array}$ \\
\hline Li-Ion & 3.6 & $80-170$ & $0.8-2$ & $\begin{array}{c}\text { Up to } \\
1200\end{array}$ \\
\hline Li-Polymer & 3.7 & $130-200$ & $1-2.8$ & $\begin{array}{c}\text { Up to } \\
1000\end{array}$ \\
\hline $\begin{array}{c}\text { Li-Iron } \\
\text { Phosphaste }\end{array}$ & $3.2 / 3.3$ & $80-115$ & $1.3-3.5$ & $\begin{array}{c}\text { Up to } \\
2000\end{array}$ \\
\hline
\end{tabular}

The Proposed Hybrid Energy Storage System is discussed in different sections like section 2 explains the different topologies of ESSs. Section 3 explains design considerations. Section 4 explains the Proposed model. Section 5 gives the comparison of simulations and Section 6 gives the conclusion.

Table 2. Characteristics of Ultra Capacitor Cells.

\begin{tabular}{|c|c|c|c|c|}
\hline Chemistry & $\begin{array}{c}\text { Nominal } \\
\text { Cell } \\
\text { Voltage } \\
\text { (Volt) }\end{array}$ & $\begin{array}{c}\text { Energy } \\
\text { Density } \\
\text { (Wh/Kg) }\end{array}$ & $\begin{array}{c}\text { Power } \\
\text { Density } \\
\text { (Kw/kg) }\end{array}$ & $\begin{array}{c}\text { Life } \\
\text { cycle } \\
\text { (Times) }\end{array}$ \\
\hline UC & $2.5 / 2.7$ & $2-30$ & $4-10$ & $\begin{array}{c}\text { Over } \\
1000000\end{array}$ \\
\hline
\end{tabular}

\section{Hybrid Energy Storage Systems}

Batteries and ultra capacitors are both electrochemical devices. However, the working principles of both of these devices are dissimilar, resulting in significant differences in their properties. batteries have a relatively high energy density, which varies with chemistry and power density [1]. On the other side, Ultracapacitor has a lower energy density and higher power density. As discussed in Table 2, the life cycle of the UC is more than one million, when compared to the batteries that are much higher. Also, when compared to the batteries UCs have the best low-temperature performance. These characteristics help in achieving the improvement of the overall performance of the system.

A number of designs have been proposed in the literature for a HESS made up of a battery pack and an ultracapacitor module, which differ from one another mostly owing to the power electronic converters involved [7-10]. Energy management capabilities and HESS exploitation may improve as the number of power electronic converters grows.

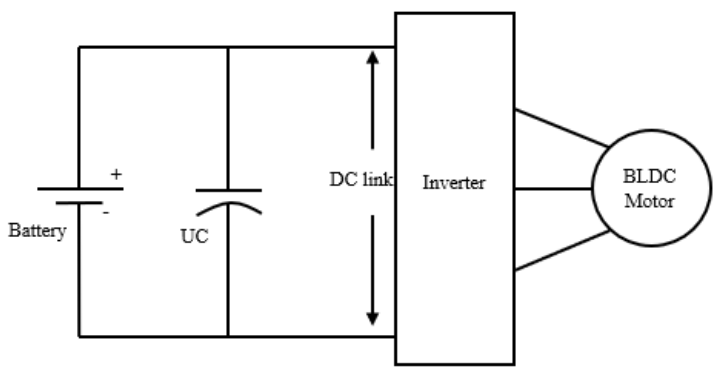

Fig.1. Parallel hybrid Basic configuration.

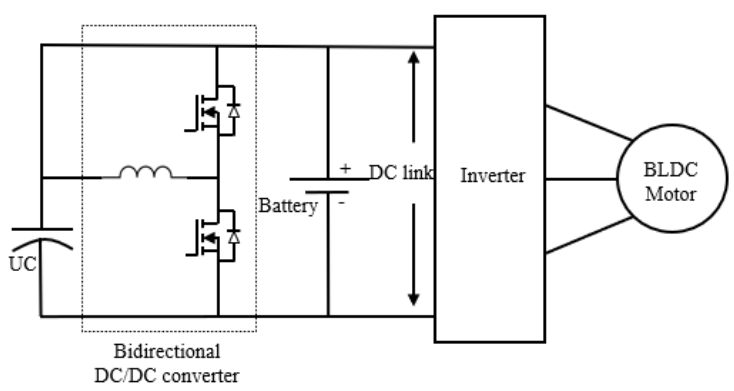

Fig.2. UltraCapacitor/battery hybrid configuration.

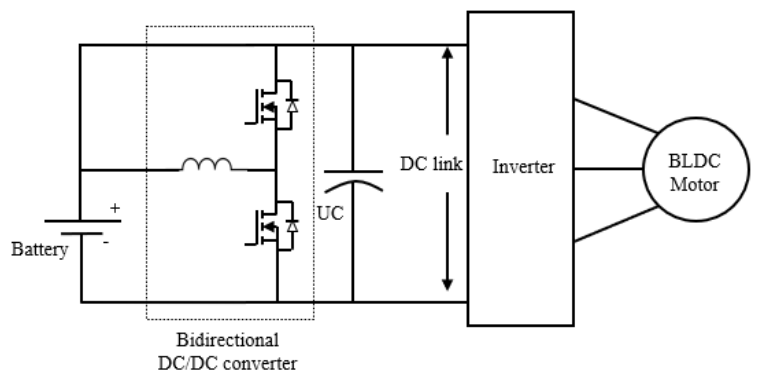

Fig. 3. Battery/UC hybrid configuration.

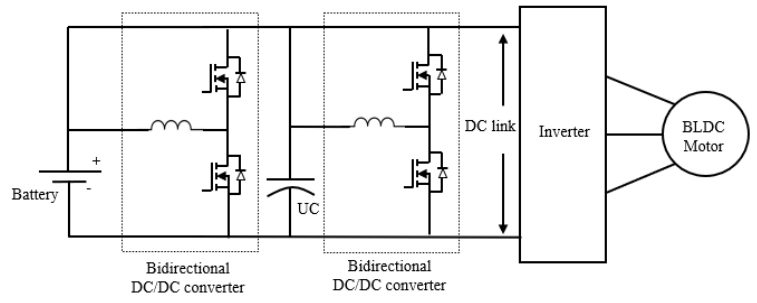

Fig. 4. Cascaded hybrid Configuration.

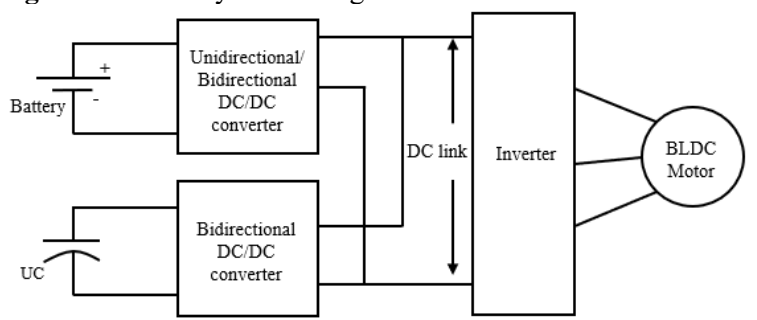

Fig. 5. Multiple Converter hybrid Configuration. 


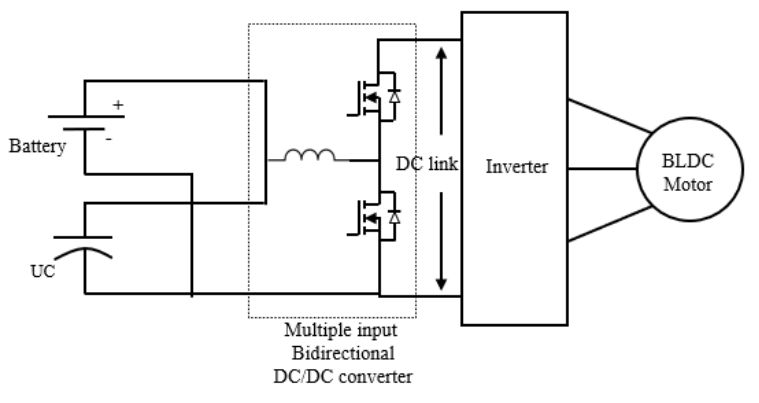

Fig. 6. Multiple Input Converter Configuration.

For the Battery and UC combinations, different connections can be made. In which basic parallel connection, Shown in Fig.1. Without the use of a convertor, the battery and the UC are connected in parallel. But with this type of connection, the stored energy of UC cannot be utilized. Another one is the Battery and UC is connected with the Bidirectional converter. The connection of Battery and Ultra capacitor as shown in Fig. 3, can utilize the UC energy in the wide range, and also battery voltage can be maintained at various ranges with respect to UC [3]. To achieve a better working, a cascaded connection of a Bidirectional converter should use. There are other configurations like Fig. 5. Which shows Multiple converter configuration and Fig. 6. shows Multiple input converter configuration.

\section{Design Considerations}

\subsection{Voltage Strategy}

In the design of a Hybrid Energy Storage System Voltage, strategy selection is related to the battery and UCs characteristics. A voltage trade-off between the storage devices should be made based on this. Ultra capacitors are often easier to balance and have reduced prices. The voltage approach used has a major impact on the topology of a HESS.

Further, $\mathrm{V}_{\mathrm{UC}}$ stands for the UC bank's voltage, $\mathrm{V}_{\mathrm{Batt}}$ for the battery pack's voltage and $V_{D C}$ for the dc-link voltage, If $\left(\mathrm{V}_{\mathrm{UC}}<\mathrm{V}_{\mathrm{Batt}}=\mathrm{V}_{\mathrm{DC}}\right)$ then battery pack is connected directly to the dc link and UC is connected to the dc-link via dc/dc converter [1]. Both the $\mathrm{dc} / \mathrm{dc}$ converter and the UC power ratings must be matched in this case in order to fully use the UC's higher power capabilities. This voltage strategy advantage is to utilize the entire $\mathrm{UC}$ range. If $\left(\mathrm{V}_{\mathrm{Batt}}<\mathrm{V}_{\mathrm{UC}}=\mathrm{V}_{\mathrm{DC}}\right)$, here we switch the positions of the UC and the battery when compared to the previous case. Now the UC bank is linked directly to the dc link, while the battery pack is connected via a $\mathrm{dc} / \mathrm{dc}$ converter to the dc link. In this case, the battery pack voltage may be kept at a lower level, resulting in fewer balance difficulties. If $\left(\mathrm{V}_{\text {Batt }}=\right.$ $\mathrm{V}_{\mathrm{UC}}=\mathrm{V}_{\mathrm{DC}}$ ), Both the UC and the battery are paralleled and linked to the dc link in this situation. This voltage strategy advantage is that there is no need for a dc/dc converter as the UC range of working is very small. If $\left(\mathrm{V}_{\mathrm{Batt}} \neq \mathrm{V}_{\mathrm{UC}} \neq \mathrm{V}_{\mathrm{DC}}\right)$ in this scenario Power electronic converters or other methods are used to connect the UC bank and the battery pack to dc-link.

\subsection{Utilization of UC stored Energy Effectively}

The UC energy storage obeys the law of storage in a normal capacitor since voltage is not a function of energy delivery in a battery.

$$
E_{\text {cap }}=\frac{1}{2} C V^{2}
$$

To transfer 75 percent of the stored energy, the UC voltage should be drained to half of its starting voltage. In evaluating different HESS configurations the major criteria are to use the UC stored energy effectively. When a UC bank is connected to the dc-link through a $\mathrm{dc} / \mathrm{dc}$ converter, 100 percent of the energy can potentially be provided. However, a safety margin is given to prevent the imbalanced cells from reversing the charge. If voltage variations are allowed, up to $66 \%$ then $90 \%$ UC energy can be delivered. If the UC and battery are connected parallel, the UC voltage may not be changed much.

Even when the discharge is forceful (within the battery power limits) The voltage of the battery pack can only decrease to $20 \%$ of the normal value. Assume that the UC is designed to cover the nominal voltage, VMax $=\mathrm{VNom}$, and that the UC is capable of delivering complete energy of $36 \%$. Because a margin must be given for the UC to cover the greater voltage of the battery pack during charging or regenerative braking, the real energy available is less than $36 \%$ [1].

\subsection{Battery Protection}

The use of the maximum power limitations of the UC to assist the accelerating process and through regenerative braking we should fully recover energy is a significant concern in the design of the proposed hybrid energy storage system. Some applications like laptops draw predictable and relatively constant currents from the battery. Energy Storage Sytems in applications like automobiles go through regular charging and discharging cycles. The unpredictable regenerative braking causes these frequent charges which are typically current surges. Without regulating these surges if they are injected into the battery directly, it may damage very quickly. Incase of lithium-ion batteries this is especially true [1].

We can solve the battery ESS problem by giving the controller charging and discharging power limitations. The charging power limitations compel the hybrid controller to activate the mechanical brake early to absorb the amount of extra energy that cannot be absorbed by the battery, while the discharging power restriction guarantees that no further power is pulled from the battery during rapid acceleration [1]. By this process, we can protect the battery from overcurrent and we can also improve the overall performance of the proposed model.

In this proposed HESS there are two components that increase the cost of the system. They are UC and dc/dc converter. Even though UC plays a major in increasing the Energy density, Dc/dc converter power handling capacity is another major factor that increases overall cost of the system. To maintain heat of the system 
thermal management should be implemented which also influences the cost of HESS. However, there will be a cost difference for the better performance of the overall system.

\section{Proposed Model}

The proposed hybrid energy storage system has a battery connected parallel to the ultracapacitor through the bidirectional $\mathrm{dc} / \mathrm{dc}$ converter following with inverter circuit and load whose simulation results are shown. Through this, we can perform different modes of operations. Fig.7. shows the connection of the proposed configuration.

The $\mathrm{dc} / \mathrm{dc}$ converter is set to keep the UC voltage greater than the battery voltage at all times. As a result, the diode is usually reverse biased [4-6].

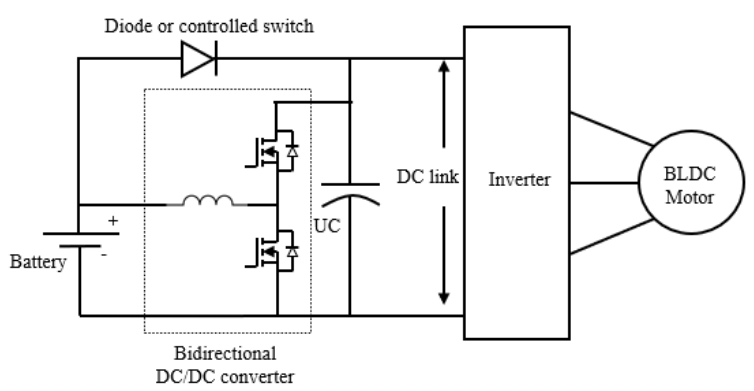

Fig. 7. Proposed Configuration.

At different speeds of the vehicle, there will be fluctuations in the battery power, to recover the fluctuations and to improve the battery life the Ultra Capacitor is placed in parallel to the battery via Bidirectional dc/dc converter. So that UC absorbs the fluctuations from the load and maintains a smooth load profile for the battery.

In this Proposed connection, Battery will charge the ultracapacitor and also supply voltage to the Motor. Depending on the load side power demand different mode of operations is done. The total operation of electric vehicles will be made in three different modes. All these modes take place in the proposed model shown in Fig. 7.

\section{Low-speed operation mode:}

As converter power is greater than demand power. So, at low constant speed operation Because the voltage across the Ultra capacitor is higher than the voltage across the battery, the power diode is disabled, and the battery supplies power to the motor via the inverter without any discharge or charge process of UC [3].

High-speed operation mode:

In case, if the demand power is higher than the converter power, it is a high-speed operation. So, at high constant speed operation, When the $\mathrm{dc} / \mathrm{dc}$ converter is switched off, the power diode is turned on and battery supply power demand directly to the motor through power diode [1].

Acceleration and Deceleration mode:
In acceleration mode, for initial starting period both $\mathrm{UC}$ and battery supply power demand to the motor, but after some time UC will discharge up to the voltage level of the battery [3]. So, after that battery will provide the energy to charge the UC and as well as the drive system.

In deceleration or regenerative braking mode operation, both battery and reverse energy from the inverter will be used to charge the UC. UC will be charged from the battery up to its voltage level, after that only reverse energy will be used to charge the UC.

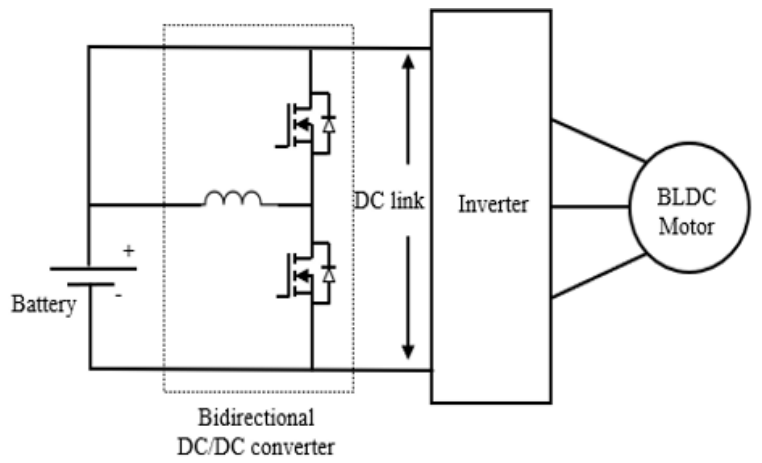

Fig. 8. Only Battery Configuration.

Fig. 8. Shows the Only Battery Configuration consists of a Battery through the Bidirectional $\mathrm{dc} / \mathrm{dc}$ converter connected to the DC link. Then the performance of the Proposed model(Fig. 7.) is compared with the Only Battery configuration(Fig. 8.) and UC/Battery configuration(Fig. 2.). we can observe the difference in Battery power and UC power fluctuations in the graphs. A Comparison of simulation results is presented below.

\section{Comparision of Simulation results}

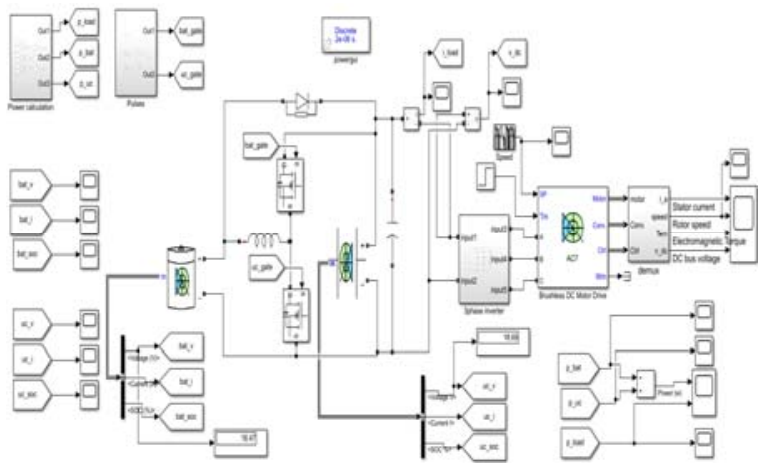

Fig. 9. Simulation setup for the Proposed model.

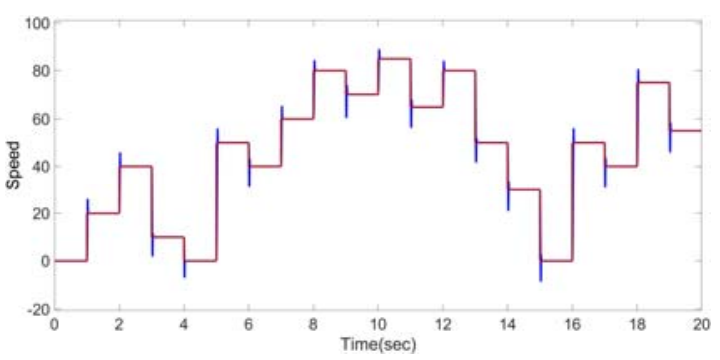



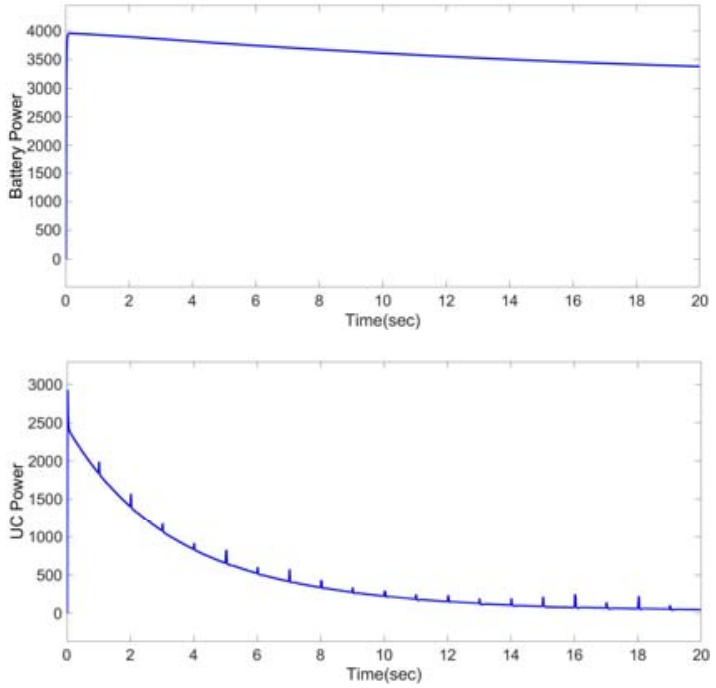

Fig. 10. Simulation results for the proposed model.

From the above Fig. 10. Proposed model it can be oserved that when there is a speed variation in the vehicle, the variations and fluctuations are observed by the UC and a smooth load profile is created for the Battery power.

In comparision to the proposed model simulation results in Only Battery configuration Fig. 12. It can be observed that when there is a speed variation in the vehicle, the Battery power fluctuations are high which will effect the Battery life and performance.

As shown in Fig. 14. Which is UC/Battery configuration, as UC is placed first all the UC power got utilised instantly and begins charging from battery power we can observe the graphs where Battery power got discharged and UC power is improved. In this configuration also Battery life cycles will be effected and overall battery performance will be reduced.

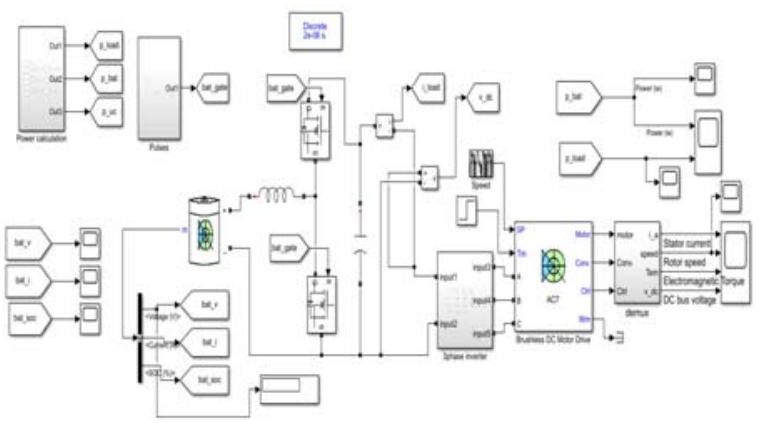

Fig. 11. Simulation diagram of Only Battery Configuration.

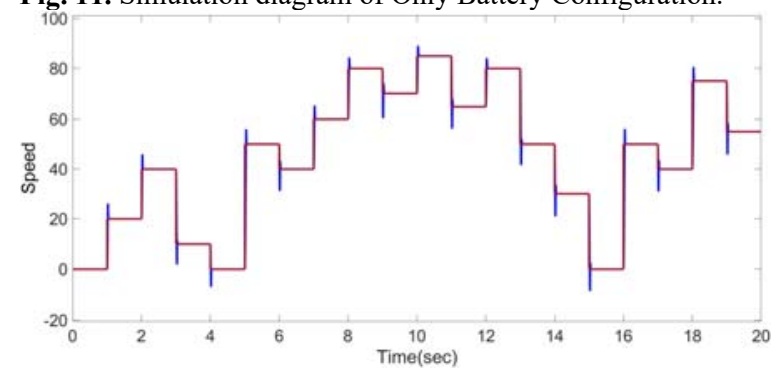

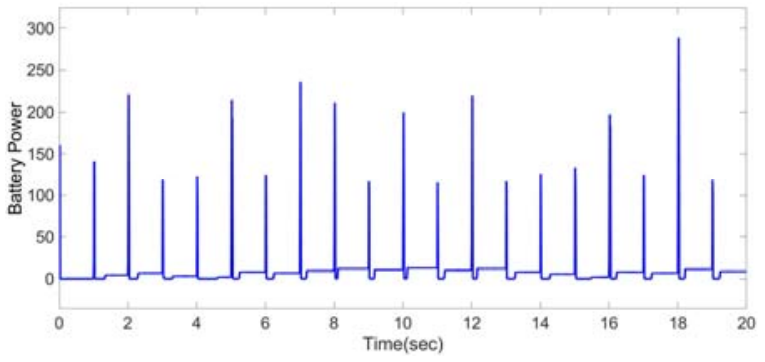

Fig. 12. Simulation results for Only Battery configuration.

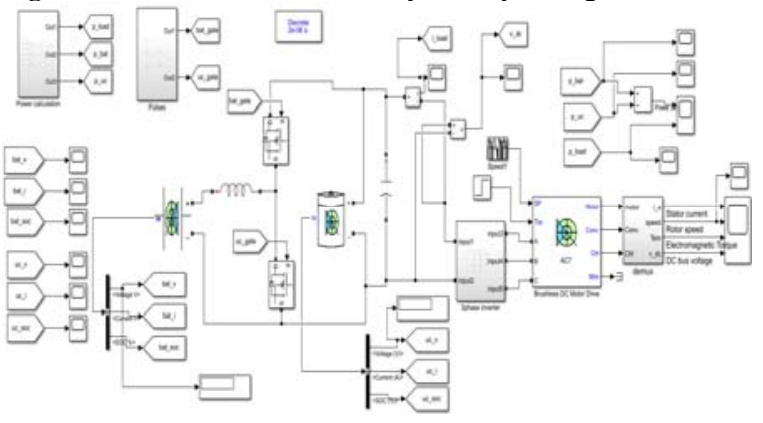

Fig. 13. Simulation diagram of UC/Battery Configuration.
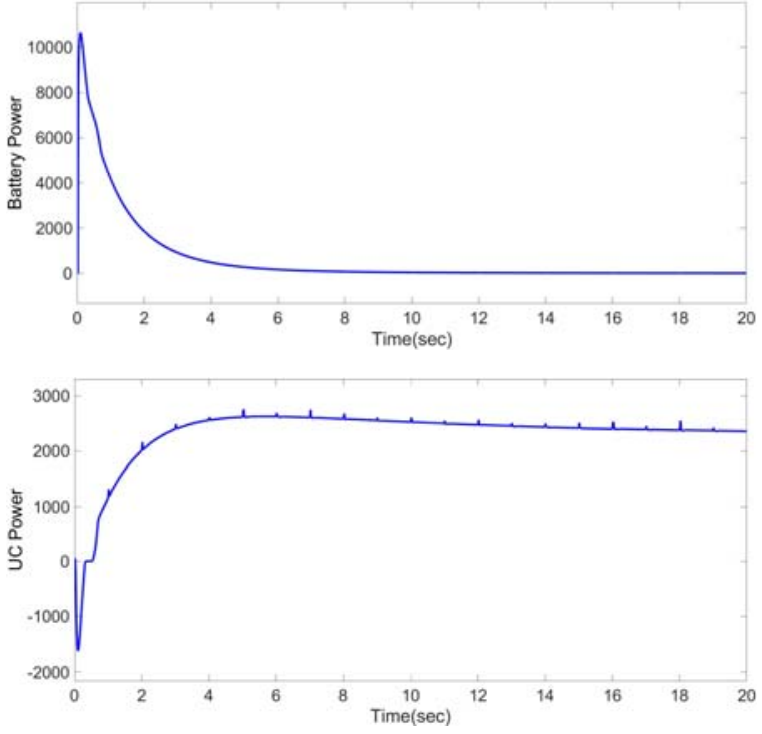

Fig. 14. Simulation results for UC/Battery Configuration

\section{Conclusion}

This paper shows the Analysis of the Hybrid Energy Storage System (HESS) using a Bidirectional dc/dc converter for different Hybrid electric vehicles. The analysed model is discussed and compared with the different configurations of the HESS. The Proposed model is used for utilization of the maximum power limits of the UC and battery and to collect energy from regenerative braking in order to increase efficiency. From the comparision of simulation results, We can observe the comparison and difference in Battery power. A smooth load profile can be created for the battery pack as shown in Fig. 10. So that battery pack power requirement can be reduced. Different modes of operations of HESS were discussed. Also, a comparison 
between the proposed model and conventional models is shown in the simulation results. By this proposed hybrid energy storage system overall efficiency of the Battery can be improved.

\section{References}

1. Jian Cao and Ali Emadi, IEEE Trans. Pow. Elec., 27 (2012).

2. J. Fang, Y. Tang, Hongchang Li, and Xiaoqiang Li IEEE Trans. Pow. Elec., 33, (2018).

3. Parth Patel, Krishna Patel and Pavak Mistry, Int. J. Sci. Engg. Res., 1, 3, (2016).

4. Alessandro Serpi, Mario Porru and Alfonso Damiano. InTech Open, 73671, 2018.

5. S. Piriienko, A. Balakhontsev, A. Beshta, A. Albu, S. Khudoliy, Pow. Elect. Dri. 1, pp 111-97 (2016).

6. Geetha Reddy Evuri, G. Srinivasa Rao, T. Ramasubba Reddy, K. Srinivasa Reddy, Int. J. Rec. Tech. Engg., 7, (2019).

7. Mr. Kushaldeep Sharma, Gopal Meena, Ashutosh Saad, Int. Res. J. Engg Tech., 05 (2018).

8. M.A. Hannan, M.M. Hoqueb,c, A. Mohamed, and A. Ayob, Renw. Sust. Engy Rev.. (2017).

9. Ching-Ming Lai, Yu-Huei Cheng, Ming-Hua Hsieh, and Yuan-Chih Lin, IEEE Trans. Veh. Tech.,67, pp. 1036-1052, (2018).

10. Roshni Lal, Abhishake Jain, Int. J. Rec. Tech. Engg 8, (2019). 